ABDIMAS: Jurnal Pengabdian Masyarakat Universitas Merdeka Malang
Vol.6(4) November 2021, 526-533
p-ISSN: 2721-138X e-ISSN: 2548-7159
http://jurnal.unmer.ac.id/index.php/jpkm

\title{
Improved health education for pregnant women in performing antenatal care in the COVID-19 pandemic
}

\section{Peningkatan pendidikan kesehatan ibu hamil dalam melakukan antenatal care pada pandemi COVID-19}

\author{
Lestari Sudaryanti1 ${ }^{1,3}$, Amellia Mardhika ${ }^{1,2}$, Arina Qona'ah², Anestasia Pangestu Mei Tyas', \\ Muhammad Ardian Cahya Laksana ${ }^{3}$ \\ ${ }^{1}$ Fakultas Vokasi, Universitas Airlangga, Surabaya \\ Jl. Dharmawangsa Dalam No. 28-30 (Kampus B) Surabaya, 60286, Indonesia \\ ${ }^{2}$ Fakultas Keperawatan, Universitas Airlangga, Surabaya \\ Jl. Mulyorejo (Kampus C) Surabaya, 60115, Indonesia \\ ${ }^{3}$ Fakultas Kedokteran, Universitas Airlangga, Surabaya \\ Jl. Mayjen Prof. Dr. Moestopo No.47 Surabaya, 60286, Indonesia
}

\begin{abstract}
ARTICLE INFO
Received: 2021-02-11

Revised: 2021-03-16

Accepted: 2021-06-11

\section{Keywords:}

Antenatal, COVID-19, Health education

\section{ABSTRACT}

COVID-19 has been declared by WHO as a global pandemic. COVID-19 affects various lines of human life, especially the health aspect. East Java has ranked second in the COVID-19 cases in Indonesia. One of the efforts made to reduce the spread of COVID-19 is through clean and healthy activities and behaviors stay at home causes people to be limited in their activities except for very important purposes, especially activities for pregnant women. Pregnant women must and should carry out regular antenatal care checks. COVID-19 causes anxiety problems and worries for pregnant women to leave the house, including having pregnancy checks. But the mother is also worried about the condition and development of the fetus. This will increase the risk of maternal and infant mortality and the SDGs target in the third objective will not be met. This community service aims to provide knowledge related to antenatal care to high-risk using Poedji Rochyati Score Card (score 6-10) and very high-risk pregnant women (score >12) during the COVID-19 period. The method used in the implementation of this community service is material from resource persons, implementation of health education, and evaluation. The pregnant women were very enthusiastic about participating in this event, it was seen from the questions given to the team and vice versa. The results of the questionnaire show that there are differences in the level of knowledge of pregnant women for pre-test and post-test.
\end{abstract}

(C)2021 Published by University of Merdeka Malang. This is an open access article distributed under the CC BY-SA 4.0 license (https://creativecommons.org/licenses/by-sa/4.0/)

How to cite: Sudaryanti, L., Mardhika, A., Qona'ah, A., Tyas, A. P. M., \& Laksana, M. A. C. (2021). Improved health education for pregnant women in performing antenatal care in the COVID-19 pandemic. Abdimas: Jurnal Pengabdian Masyarakat Universitas Merdeka Malang, 6(4), 526-533. https://doi.org/10.26905/abdimas.v6i4.5447

\section{PENDAHULUAN}

COVID-19 di Indonesia pada penghujung tahun 2020 terdapat 743.198 kasus terkonfirmasi, dimana Jawa Timur menduduki peringkat kedua dengan 84.152 kasus (11,3\%). Kasus terkonfirmasi 
dengan kondisi penyerta yaitu ibu hamil pada peringkat keempat di Indonesia sejumlah 8,9\% ibu hamil terkonfirmasi positif, 0,7\% dirawat/isolasi mandiri, 7,8\% ibu hamil sembuh, dan 0,3\% ibu hamil meninggal dari 2.652 data (Satgas COVID-19, 2020). Cara menekan kasus COVID-19 dengan isolasi diri bagi seseorang yang sakit, orang dalam pemantauan (ODP), dan mendapatkan tindakan (Kemenkes, 2020). Bagi seseorang yang sehat diharapkan tetap sadar dan patuh terhadap protokol kesehatan dalam mencegah COVID-19 yaitu memakai masker, menjaga jarak dan menghindari kerumunan, serta mencuci tangan menggunakan sabun (Satgas COVID-19, 2020). Stay at home merupakan pilihan yang baik saat pandemi (Setyawan \& Lestari, 2020). Namun, stay at home tidak berlaku bagi ibu hamil dikarenakan ibu hamil perlu melakukan Antenatal Care (ANC) minimal 6 kali (Kemenkes, 2020).

Desa Candisari merupakan salah satu desa di wilayah kerja Puskesmas Sambeng yang merupakan mitra Program Kemitraan Masyarakat (PKM) dimana lokasi ini berjarak 32 Km dari Prodi D3 Keperawatan Fakultas Vokasi Universitas Airlangga Kampus Lamongan. Cakupan kunjungan K4 di Kabupaten Lamongan (Dinkes Lamongan, 2018; Dinkes Lamongan, 2017) dari tahun 2017 dan 2018 yaitu 95,7\% (16.857 dari 17.615 ibu hamil), 99,7\% (17.313 dari 17.369 ibu hamil), terlihat signifikan naik dalam 2 tahun ini. Cakupan kunjungan K4 di Kecamatan Sambeng, dari tahun 2017 dan 2018 yaitu 89\% (559 dari 628 ibu hamil), 90,7\% (627 dari 691 ibu hamil). Kondisi yang sudah baik ini, harapannya juga tetap baik bahkan meningkat meskipun dalam kondisi pandemi. Kondisi Kecamatan Sambeng pada tanggal 14-27 Desember 2020 mempunyai angka risiko sedang untuk kenaikan kasus COVID-19 (terkonfirmasi 3 orang dan suspek 4 orang) (Dinkes Lamongan, 2020).

COVID-19 pada tahun 2020 merupakan kasus yang telah menjadi pandemi di dunia. Hal ini merubah kebiasaan ibu hamil dalam melaksanakan ANC. Meskipun mendapatkan banyak informasi pada media massa, namun ibu hamil akan merasa khawatir untuk datang ke pelayanan kesehatan (Jiao, 2020). Perlunya pemberian pendidikan kesehatan yang tepat (Anikwe et al., 2019) pada ibu hamil dalam melakukan ANC pada kondisi pandemi COVID-19 akan dapat membantu pemerintah guna menurunkan kasus COVID-19 dan tetap mengedepankan kualitas pelayanan (Kementerian Kesehatan, 2020) terutama pada ibu hamil yang merupakan kasus penyerta keempat di Indonesia (Satgas COVID-19, 2020) dan dapat membantu untuk menurunkan risiko kematian ibu dan bayi sesuai dengan target SDGs (Susiana, 2019), dimana dalam tujuan ketiga yaitu kesehatan yang baik dan kesejahteraan pada target kesatu diharapkan dapat mengurangi rasio AKI menjadi kurang dari 70 per 100.000 kelahiran pada tahun 2030 (Infid, 2017)

Pendidikan kesehatan ini dilakukan satu kali dengan pemaparan video dari para ahli dan pemaparan langsung oleh tim kepada ibu hamil. Video ini nantinya akan dikemas dalam video terintegrasi (dokter, bidan, dan tim), dimana nantinya ibu hamil yang tidak dapat hadir dalam kegiatan pengabdian kepada masyarakat secara offline (karena terbatasnya tempat dengan protokol menjaga jarak). Ibu hamil dapat melihat video ini pada YouTube dimana alamat URL akan dibagikan oleh bidan desa kepada seluruh ibu hamil di Desa Candisari.

\section{METODE}

Setelah tim melakukan survei lapangan dan menganalisis permasalahan, metode yang dilakukan dalam pelaksanaan pengabdian masyarakat ini adalah pengumpulan materi dari narasumber, pelaksanaan (pendidikan kesehatan) dan evaluasi. 
ABDIMAS: Jurnal Pengabdian Masyarakat Universitas Merdeka Malang Volume 6, No. 4, November 2021: 526-533

Pada tahap pertama yaitu pengumpulan materi, tim mengumpulkan informasi dari para ahli (dokter dan bidan) dengan memberikan kisi-kisi yang akan diberikan kepada ibu hamil. Informasi ini direkam secara online menggunakan media Zoom. Setelah semua informasi terkumpul dan tertata dengan baik, kami melakukan koordinasi dengan Kepala Puskesmas dan Bidan koordinator Puskesmas Sambeng terkait pelaksanaan.

Tahap kedua adalah pelaksanaan (pendidikan kesehatan). Pendidikan kesehatan dilakukan secara offline (terbatas pada 15 ibu hamil) dengan menyesuaikan lokasi dan mengedepankan protokol kesehatan COVID-19. Kegiatan ini dilaksanakan di Balai Desa Candisari Kecamatan Sambeng Kabupaten Lamongan. Pengetahuan ibu hamil tentang pelaksanaan ANC pada situasi pandemi ini diukur pada saat sebelum (pre-test) dan sesudah (post-test) diberikan pendidikan kesehatan untuk mengetahui tingkat pengetahuan ibu hamil. Dalam acara inti, penyajian video materi dalam kegiatan penyuluhan terbatas (pendidikan kesehatan) kepada ibu hamil tentang bagaimana pelaksanaan ANC di Puskesmas, Rumah Sakit tipe B di daerah (video oleh narasumber dari RSUD Dr. Soegiri Lamongan) dan Rumah Sakit tipe B di Surabaya (video oleh narasumber dari RS Universitas Airlangga) serta penanganan kecemasan pada ibu hamil dalam kondisi pandemi COVID-19.

Tahap ketiga yang merupakan tahap terakhir yaitu tahap evaluasi. Pada tahap ini, evaluasi yang dilakukan berupa evaluasi proses dan evaluasi hasil. Evaluasi proses akan dilakukan tanya jawab oleh narasumber, tim pengabdian kepada masyarakat, dan ibu hamil. Evaluasi hasil akan diberikan kuesioner (post-test).

Bahan yang digunakan adalah LCD, laptop beserta video rekaman materi tentang pelaksanaan yang sebelumnya telah direkam dan alat penunjang lain (pengeras suara) untuk pemateri dalam memberikan pendidikan kesehatan yang diberikan secara langsung oleh Kepala Puskesmas Sambeng serta tim pengabdian kepada masyarakat untuk memberikan informasi mengenai penatalaksanaan Antenatal Care kepada ibu hamil dalam kondisi pandemi dan dilakukan evaluasi dengan tanya jawab serta membagi kertas kuesioner (pre-test dan post-test). Pengetahuan ibu hamil tentang pelaksanaan ANC pada situasi pandemi ini diukur pada saat sebelum (pre-test) dan sesudah (post-test) diberikan pendidikan kesehatan untuk mengetahui tingkat pengetahuan ibu hamil. Data yang telah terkumpul akan diuji menggunakan Uji Wilcoxon Signed Ranks Test.

\section{HASIL DAN PEMBAHASAN}

\section{Hasil}

Tujuan yang ingin dicapai dalam kegiatan ini adalah memberikan pendidikan kesehatan pada ibu hamil dalam melakukan Antenatal Care pada kondisi pandemi COVID-19 untuk meningkatkan pengetahuan masyarakat khususnya ibu hamil. Tingkat pengetahuan ibu hamil sebelum diberikan pendidikan kesehatan (pre-test) dengan hasil sebagian kecil mempunyai pengetahuan kurang $(6,7 \%)$ dan hampir separuh mempunyai pengetahuan baik $(46,7 \%)$. 
Improved health education for pregnant women in performing antenatal care in the COVID-19 pandemic Lestari Sudaryanti, Amellia Mardhika, Arina Qona'ah, Anestasia Pangestu Mei Tyas, Muhammad Ardian Cahya Laksana

Tabel 1. Distribusi frekuensi hasil pre-test tingkat pengetahuan ibu hamil dalam melakukan ANC pada kondisi pandemi COVID-19

\begin{tabular}{lcc}
\hline Kategori & Jumlah (f) & Persentase (\%) \\
\hline Baik & 7 & 46,7 \\
Cukup & 7 & 46,7 \\
Kurang & 1 & 6,7 \\
\hline Total & $\mathbf{1 5}$ & $\mathbf{1 0 0}$
\end{tabular}

Tingkat pengetahuan ibu hamil setelah diberikan pendidikan kesehatan (post-test) dengan hasil tidak satupun mempunyai pengetahuan kurang (0\%) dan sebagian kecil mempunyai pengetahuan cukup $(13,3 \%)$ serta hampir seluruhnya berpengetahuan baik $(86,7 \%)$.

Tabel 2. Distribusi frekuensi hasil post-test tingkat pengetahuan ibu hamil dalam melakukan ANC pada kondisi pandemi COVID-19

\begin{tabular}{lcc}
\hline Kategori & Jumlah (f) & Persentase (\%) \\
\hline Baik & 13 & 86,7 \\
Cukup & 2 & 13,3 \\
Kurang & 0 & 0 \\
\hline Total & $\mathbf{1 5}$ & $\mathbf{1 0 0}$ \\
\hline
\end{tabular}

Tabel 3. Hasil uji Wilcoxon Signed Ranks Test

\begin{tabular}{llrrrrr}
\hline & & N & Mean Rank & $\begin{array}{c}\text { Sum of } \\
\text { Ranks }\end{array}$ & Z & $\begin{array}{c}\text { Asymp. Sig. } \\
\text { (2-tailed) }\end{array}$ \\
\hline & Negative Ranks & $0^{\mathrm{a}}$ & .00 & .00 & $-2.333^{\mathrm{a}}$ & .020 \\
Post pengetahuan - Pre & Positive Ranks & $6^{\mathrm{b}}$ & 3.50 & 21.00 & & \\
pengetahuan & Ties & $9 \mathrm{c}$ & & & \\
& Total & $\mathbf{1 5}$ & & & \\
\hline
\end{tabular}

a. post pengetahuan < pre pengetahuan

b. post pengetahuan $>$ pre pengetahuan

c. post pengetahuan = pre pengetahuan

Hasil analisis pada Tabel 3 menunjukkan bahwa negative ranks atau selisih (negatif) antara hasil pre-test dan post-test tingkat pengetahuan ibu hamil adalah 0 , baik itu pada nilai $\mathrm{N}$, mean rank, maupun sum rank. Nilai 0 ini menunjukkan tidak ada penurunan dari nilai pre-test ke nilai post-test. Positive ranks atau selisih (positif) antara pre-test dan post-test tingkat pengetahuan ibu hamil. Terdapat 6 data positif (N) yang artinya 6 responden mengalami peningkatan tingkat pengetahuan dari nilai pre-test ke nilai post-test. Rata-rata peningkatan tersebut adalah 3.50, sedangkan jumlah ranking positif adalah 21 . Ties adalah kesamaan nilai pre-test dan post-test adalah 9 sehingga dapat dikatakan ada nilai yang sama antara pre-test dan post-test. Berdasarkan hasil di atas menunjukkan nilai asymp.sig.(2-tailed) adalah 0.020 ( $p<0.05$ ) maka HO ditolak artinya ada perbedaan antara tingkat pengetahuan pada ibu hamil untuk pre-test dan post-test. 
ABDIMAS: Jurnal Pengabdian Masyarakat Universitas Merdeka Malang

Volume 6, No. 4, November 2021: 526-533

\section{Pembahasan}

COVID-19 pada tahun 2020 merupakan kasus yang telah menjadi pandemi di dunia. Hal ini mengubah kebiasaan ibu hamil dalam melaksanakan Antenatal Care (ANC). Meskipun mendapatkan banyak informasi pada media massa, namun ibu hamil akan merasa khawatir untuk datang ke pelayanan kesehatan (Jiao, 2020). Jika hal ini dibiarkan maka akan menambah Angka Kematian Ibu (AKI) di Indonesia, dimana angka yang masih tinggi dari tahun 1991 hingga 2015 (390 hingga 305 per kelahiran hidup). Berdasarkan model yang ditetapkan oleh Kementerian Kesehatan Republik Indonesia, AKI diperkirakan turun menjadi 131 per 100.000 kelahiran hidup (Kemenkes RI, 2019).

Perlunya pemberian pendidikan kesehatan yang tepat (Anikwe et al., 2019) pada ibu hamil dalam melakukan ANC pada kondisi pandemi COVID-19 akan dapat membantu pemerintah guna menurunkan kasus COVID-19 dan tetap mengedepankan kualitas pelayanan (Kementerian Kesehatan, 2020) terutama pada ibu hamil yang merupakan kasus penyerta keempat di Indonesia (Satgas COVID-19, 2020) dan dapat membantu untuk menurunkan risiko kematian ibu dan bayi sesuai dengan target SDGs (Susiana, 2019), dimana dalam tujuan ketiga yaitu kesehatan yang baik dan kesejahteraan (good health and wellbeing), pada target pertama diharapkan dapat mengurangi rasio AKI menjadi kurang dari 70 per 100.000 kelahiran pada tahun 2030 (Infid, 2017).

Terdapat perbedaan antara tingkat pengetahun ibu hamil untuk pre-test dan post-test. Hal ini menunjukkan bahwa pendidikan kesehatan ini perlu diberikan baik dalam kegiatan tatap muka maupun menggunakan media oleh petugas kesehatan meskipun ibu hamil merasa enggan dan khawatir untuk datang ke pelayanan kesehatan (Jiao, 2020). Pengetahuan ibu hamil tentang COVID-19 masih jauh dari kenyataan dan hal ini dipengaruhi oleh kekhawatiran dan tekanan psikologis ibu hamil (Derya et al., 2021) dikarenakan takut tertular COVID-19 (Kementerian Kesehatan, 2020, namun ANC harus tetap dilakukan (Kemenkes RI, 2020), dimana ANC ini dapat meminimalkan AKI dengan melakukan pemeriksaan secara berkala kepada ibu dan janinnya.

Pendidikan kesehatan ini diperlukan karena dalam pertanyaan kuesioner yang telah dijawab ibu hamil saat kegiatan pengabdian kepada masyarakat di Desa Candisari, terdapat jawaban bahwa dalam kondisi pandemi tidak diperkenankan melakukan kunjungan (ANC) ke pelayanan kesehatan. Hal ini berbanding terbalik dengan pedoman buku KIA tahun 2020, bahwa ANC dilaksanakan minimal 6 kali selama kehamilan (Kemenkes, 2020). Pelayanan ANC ini perlu dilakukan terutama pada ANC trimester pertama dimana dilakukan screening faktor risiko oleh dokter dengan tetap menerapkan protokol kesehatan dan sebelum melakukan kunjungan ANC secara tatap muka, perlu dilakukan janji temu atau teleregistrasi dengan screening anamnesa, dapat melalui media komunikasi telepon atau secara daring untuk mencari faktor risiko dan gejala COVID-19 (Kementerian Kesehatan, 2020). BPJS saat ini juga memfasilitasi screening COVID-19 dengan aplikasi mobile JKN. Aplikasi ini juga sangat membantu pengguna layanan BPJS dalam mengambil nomor antrian agar tidak terlalu lama menunggu di pelayanan kesehatan (Wisnubroto, 2020) .

Pengetahuan yang baik tentang bagaimana menggunakan pelayanan kesehatan dalam kegiatan ANC, melaksanakan protokol kesehatan selama pandemi dengan menggunakan masker, mencuci tangan, menjaga jarak, etika batuk yang benar, kebersihan lingkungan, dan mendesinfeksinya merupakan upaya agar terhindar dari COVID-19 (World Health Organization et al., 2020) dan dapat memperkecil risiko AKI. Gambar 1 adalah alur pelayanan ibu hamil yang akan melakukan ANC pada era adaptasi kebiasaan baru. 
Improved health education for pregnant women in performing antenatal care in the COVID-19 pandemic Lestari Sudaryanti, Amellia Mardhika, Arina Qona'ah, Anestasia Pangestu Mei Tyas, Muhammad Ardian Cahya Laksana

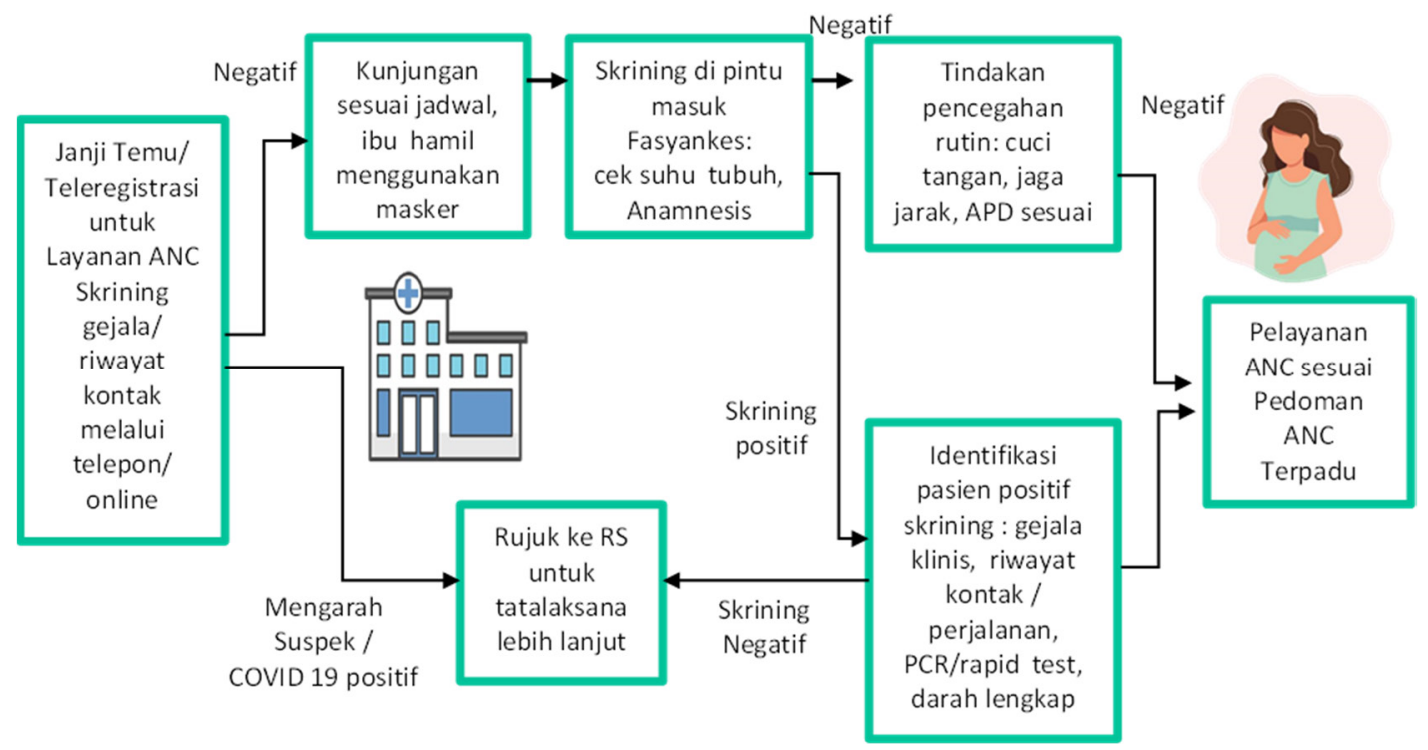

Gambar 1. Alur pelayanan ibu hamil era adaptasi kebiasaan baru (Pemaparan Muhammad Ardian C.L., dr., SpOG(K)., M.Kes)
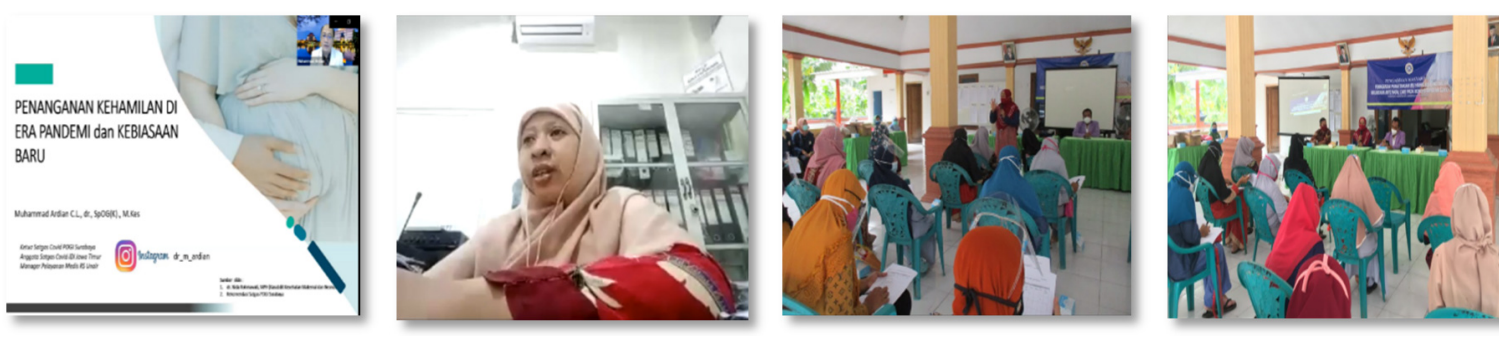

Gambar 2. Pengumpulan materi oleh narasumber (menggunakan Zoom) Gambar 3. Pemberian kuesioner (pre-test)
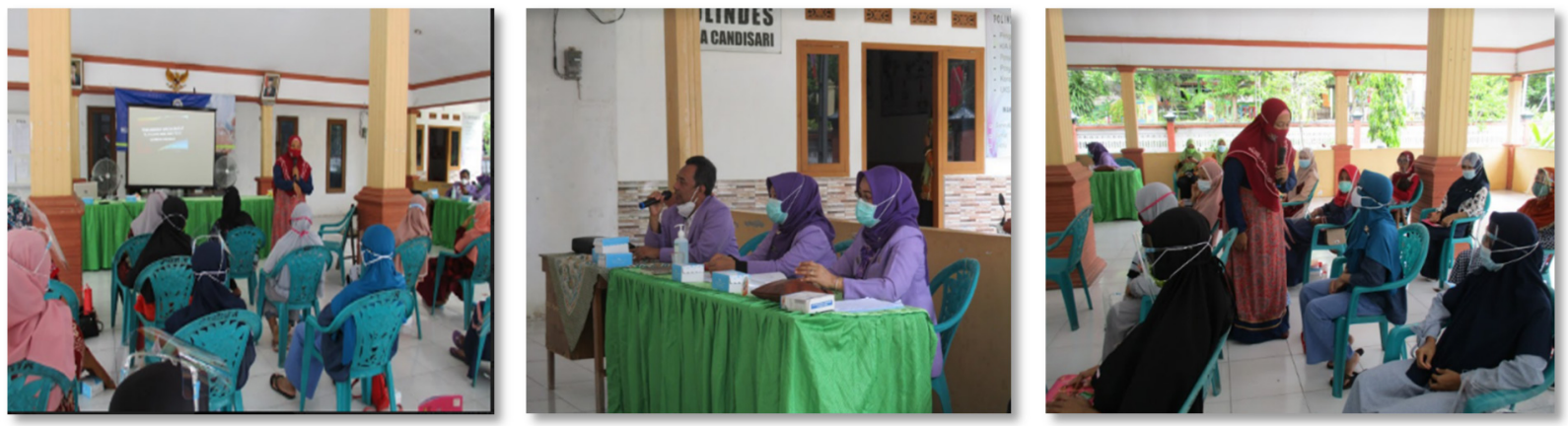

Gambar 4. Pendidikan kesehatan kepada ibu hamil 

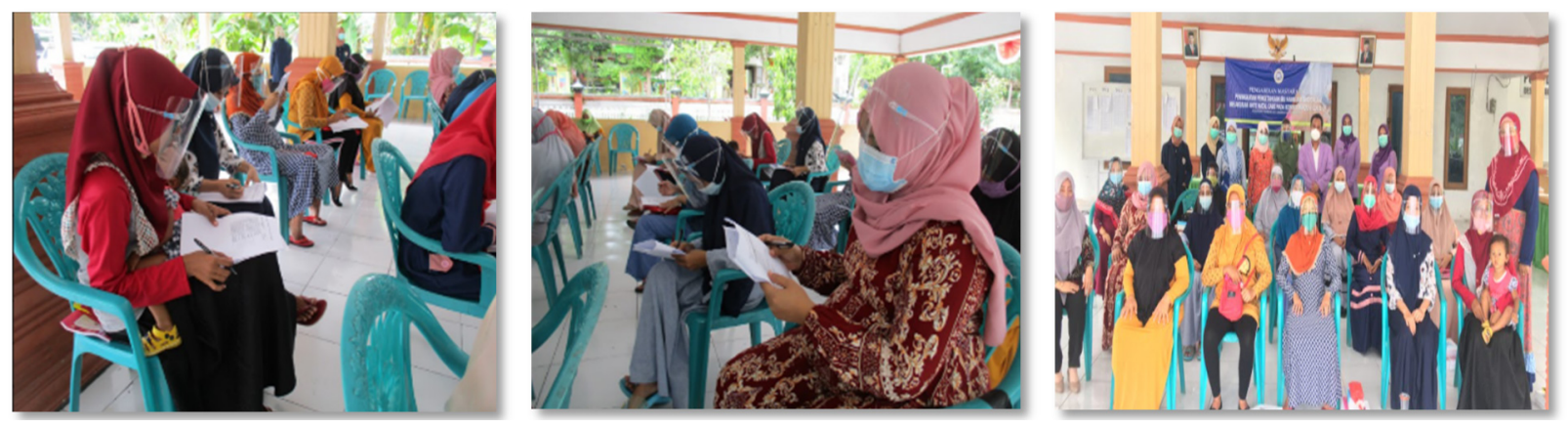

Gambar 5. Evaluasi (tanya jawab) dan pemberian kuesioner (post-test)

\section{SIMPULAN DAN SARAN}

Berdasarkan kegiatan peningkatan pendidikan kesehatan bagi ibu hamil dalam melakukan ANC pada kondisi pandemi COVID-19 ini, dapat diambil kesimpulan bahwa pada saat situasi pandemi ini tidak terdapat kendala dalam tahap pengumpulan materi dari para ahli dengan dimudahkannya media online seperti Zoom. Pada tahap pelaksanaan (pendidikan kesehatan), masyarakat sangat antusias mengikuti jalannya acara. Antusias ibu hamil terlihat dari pertanyaan-pertanyaan yang diberikan kepada tim begitu pula sebaliknya. Hasil dari kuesioner ada perbedaan antara tingkat pengetahuan pada ibu hamil untuk pre-test dan post-test.

Keterbatasaan saat pelaksanaan pendidikan kesehatan terletak pada terbatasnya jumlah peserta akibat pandemi dan tidak adanya interaksi secara langsung antara masyarakat dengan beberapa narasumber (hanya melalui rekaman Zoom). Selain itu, Zoom tidak dapat dilakukan dikarenakan terkendala sinyal. Saran untuk pengabdi selanjutnya dalam rangka meningkatkan efektivitas dari program pengabdian masyrakat terkait ANC pada ibu hamil maka kegiatan dapat dilakukan dalam beberapa sesi, terprogram, dan berkelanjutan serta pemberian materi disampaikan secara offline dengan tetap mengedepankan protokol kesehatan. Dibentuknya grup WA (WhatsApp) antara pengabdi dengan kader dan kader dengan ibu hamil, dimana informasi terbaru akan dapat tersampaikan, pemantauan jadwal ANC oleh kader kepada ibu hamil agar tetap dilaksanakan sesuai jadwal dan kesehatan ibu hamil dapat terpantau dengan baik. Penyegaran dalam melaksanakan deteksi dini risiko ibu hamil dengan menggunakan KSPR (Kartu Skor Poedji Rochjati) untuk kader juga perlu diberikan, agar dapat membantu ibu hamil dalam menentukan pemeriksaan ANC selanjutnya.

\section{UCAPAN TERIMAKASIH}

Ucapan terimakasih disampaikan kepada Rektor dan Ketua Lembaga Penelitian dan Inovasi (LPI) Universitas Airlangga atas dukungan dana melalui Hibah Riset Mandat Khusus COVID-19 dimana dana ini juga diperuntukkan dalam kegiatan pengabdian kepada masyarakat. Terimakasih disampaikan kepada pemateri dari RS Universitas Airlangga, RSUD Dr. Soegiri Lamongan, Kepala Puskesmas Sambeng, Bidan Koordinator, Kepala Desa Candisari beserta Kader dan terimakasih disampaikan kepada ibu hamil yang telah meluangkan waktu untuk hadir dalam kegiatan ini. Semoga menjadikan keberkahan untuk kita semua. 


\section{DAFTAR PUSTAKA}

Anikwe, C. C., Ogah, C. O., Anikwe, I. H., Okorochukwu, B. C., \& Ikeoha, C. C. (2020). Coronavirus disease 2019: Knowledge, attitude, and practice of pregnant women in a tertiary hospital in Abakaliki, southeast Nigeria. International Journal of Gynecology \& Obstetrics, 151(2), 197-202. https://doi.org/10.1002/ijgo.13293

Dinkes Lamongan. (2017). Profil kesehatan Kabupaten Lamongan tahun 2017. Lamongan: Dinas Kesehatan Pemerintah Kabupaten Lamongan.

Dinkes Lamongan. (2018). Profil kesehatan Kabupaten Lamongan tahun 2018. Lamongan: Dinas Kesehatan Pemerintah Kabupaten Lamongan.

Dinkes Lamongan. (2020). COVID-19 Center Lamongan. Dinas Kesehatan.

Infid. (2017). Tujuan 03 kesehatan yang baik dan kesejahteraan.

Jiao, J. (2020). Under the epidemic situation of COVID-19, should special attention to pregnant women be given? Journal of Medical Virology, 0-3. https://doi.org/10.1002/jmv.25771

Kemenkes. (2020). Surat Edaran No. HK.0201/MENKES/2020 tentang Protokol Isolasi Diri Sendiri dalam Penanganan Coronavirus Diseases (COVID-19), 1-4.

Kemenkes RI. (2019). Profil kesehatan Indonesia 2018 [Indonesia health profile 2018]. Jakarta: Kementerian Kesehatan Republik Indonesia.

Kemenkes RI. (2020). Buku kiat kesehatan ibu dan anak. Jakarta: Kementerian Kesehatan Republik Indonesia.

Kementerian Kesehatan. (2020). Pedoman pelayanan antenatal, persalinan, nifas, dan bayi baru lahir di era adaptasi kebiasaan baru. Edisi Kedua. Jakarta: Kementerian Kesehatan RI.

Satgas COVID-19. (2020a). Pedoman perubahan perilaku penanganan COVID-19. Satgas Penanganan COVID-19

Satgas COVID-19. (2020b). Peta sebaran COVID-19. Satgas Penanganan COVID-19.

Setyawan, F. E. B., \& Lestari, R. (2020). Challenges of stay-at-home policy implementation during the Coronavirus (Covid-19) pandemic in Indonesia. Jurnal Administrasi Kesehatan Indonesia, 8, 1520. http://dx.doi.org/10.20473/jaki.v8i0.2020.15-20

Susiana, S. (2019). Angka kematian ibu: Faktor penyebab dan upaya penanganannya. Bidang Kesejahteraan Sosial Info Singkat, 11(24), 13-18.

Wisnubroto, K. (2020). Mengenal layanan 6 fitur baru aplikasi mobile JKN. Indonesia.go.id. https://indonesia.go.id/kategori/kesehatan/2260/mengenal-layanan-6-fitur-baru-aplikasimobile-jkn

World Health Organization. (2020). Transmission of SARS-CoV-2: Implications for infection prevention precautions: scientific brief, 09 July 2020. World Health Organization.

Derya, Y. A, Altiparmak, S., Akça, E., Gökbulut, N., \& Yilmaz, A. N. (2021). Pregnancy and birth planning during COVID-19: The effects of tele-education offered to pregnant women on prenatal distress and pregnancy-related anxiety. Midwifery, 92, 1-116. https://doi.org/10.1016/j.midw.2020.102877 